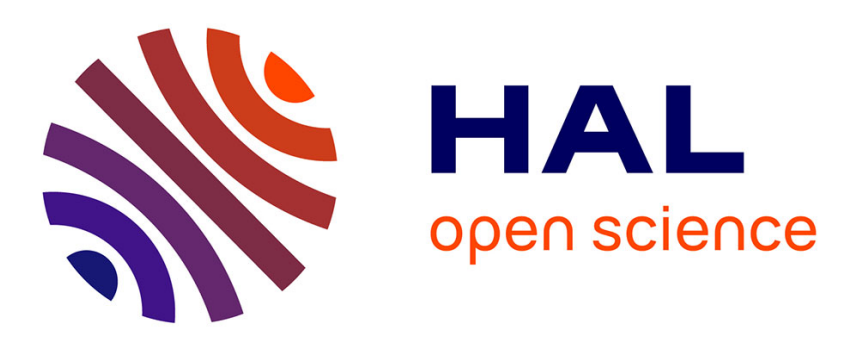

\title{
Static and dynamic polystyrene dimensions in relation to the blob model and size-exclusion chromatography \\ Z. Gallot, G. Pouyet, Anne Schmitt
}

\section{To cite this version:}

Z. Gallot, G. Pouyet, Anne Schmitt. Static and dynamic polystyrene dimensions in relation to the blob model and size-exclusion chromatography. Journal de Physique, 1983, 44 (2), pp.247-250. 10.1051/jphys:01983004402024700 . jpa-00209592

\section{HAL Id: jpa-00209592 https://hal.science/jpa-00209592}

Submitted on 1 Jan 1983

HAL is a multi-disciplinary open access archive for the deposit and dissemination of scientific research documents, whether they are published or not. The documents may come from teaching and research institutions in France or abroad, or from public or private research centers.
L'archive ouverte pluridisciplinaire HAL, est destinée au dépôt et à la diffusion de documents scientifiques de niveau recherche, publiés ou non, émanant des établissements d'enseignement et de recherche français ou étrangers, des laboratoires publics ou privés. 


\title{
Static and dynamic polystyrene dimensions in relation to the blob model and size-exclusion chromatography
}

\author{
Z. Gallot, G. Pouyet and A. Schmitt \\ Centre de Recherches sur les Macromolécules, 6, rue Boussingault, 67083 Strasbourg Cedex, France
}

(Reçu le 26 juillet 1982, révisé le 4 octobre, accepté le 13 octobre 1982)

\begin{abstract}
Résumé. - Nous avons mesuré certains paramètres de transport (sédimentation, viscosité, chromatographie d'exclusion stérique) pour une série de polystyrènes linéaires en solution dans un bon solvant : le tétrahydrofuranne. Partant de la théorie récente de Weill-des Cloizeaux, nous montrons qu'il est possible d'étudier, à partir de nos résultats expérimentaux, les variations du rayon de giration $R_{\mathrm{G}}$ avec la masse du polymère. Le bien-fondé de l'hypothèse du modèle de blob thermique est établi, et nous retrouvons les lois de puissance prévues théoriquement de part et d'autre du domaine de transition (ou cross-over spatial). En chromatographie d'exclusion stérique, nous montrons qu'il est possible d'établir plusieurs lois d'étalonnage à partir de nos données, sans qu'il soit possible d'affirmer laquelle est la plus « universelle ».
\end{abstract}

\begin{abstract}
Dynamic measurements (sedimentation, viscosity, size exclusion chromatography) were carried out on a series of polystyrene samples dissolved in a good solvent, tetrahydrofuran. Using the Weill-des Cloizeaux theory we show that it is possible, from these data, to study how the coil radius of gyration varies with molecular weight. The validity of the thermal-blob model is confirmed by our results, and the expected power laws under and above the cross-over domain are indeed observed. In size-exclusion chromatography, we observe that several calibration curves may be obtained from the experimental data.
\end{abstract}

1. Introduction - When a polymer molecule is dissolved in a good solvent, the transport parameters characterizing the coil dimensions in the limit of infinite dilution (intrinsic viscosity $[\eta]$, diffusion or sedimentation coefficients) do generally follow, as a function of molecular weight, power laws which do not agree with the results obtained in scattering experiments. This problem has recently been the subject of several theoretical investigations, and different versions of the so-called «thermal-blob model ", originally proposed by Daoud [1], have actually been worked out [2-6]. The basic argument presented by Weill-des Cloizeaux is that there are two characteristic coil dimensions, $R_{\mathrm{G}}$ (radius of gyration) and $R_{\mathrm{D}}$ (diffusion or hydrodynamic radius), related to the limiting dynamic coefficients and the molecular weight via the proportionality relations :

$$
\begin{aligned}
{[\eta] } & \sim R_{\mathrm{G}}^{2} R_{\mathrm{D}} M^{-1} \\
D & \sim R_{\mathrm{D}}^{-1} \\
S & \sim M R_{\mathrm{D}}^{-1}
\end{aligned}
$$

[ $\eta], D$ and $S$ being respectively the intrinsic viscosity, and the limiting diffusion and sedimentation coeffi- cients. However, both dimensions do not approach their asymptotic limit within the same range of polymerization degree, the statistical weight of short distances being obviously predominant in the definition of $R_{\mathrm{D}}$. In other words, both characteristic distances $R_{\mathrm{G}}$ and $R_{\mathrm{D}}$ do not show the same sensitivity to excluded-volume effects and chain statistics; thus, the related critical exponents $v_{D}$ and $v_{G}$ (see [2]) do vary with molecular weight and excluded-volume parameter, in a way which is not always monotonic, depending on the blob model chosen $[4,6]$.

In order to use dynamic studies to test the validity of the ideas developed independently in $[2,3]$, one of us [7] proposed the study of the variation with molecular weight of the product :

$$
\text { [ } \eta] D \sim R_{\mathrm{G}}^{2} M^{-1} .
$$

Using data obtained in our Laboratory [8] it was possible to show that there is a critical molecular weight range, around a value $M_{\mathrm{c}}$, typical of a spatial crossover between ideal chain statistics $\left(M<M_{\mathrm{c}}\right)$ and excluded-volume statistics $\left(M>M_{\mathrm{c}}\right)$.

The aim of the present paper is twofold; first, it is 
to substantiate the foregoing observations with additional experiments; second, it is to analyse whether the different molecular dimensions, calculated from transport coefficients, are equivalent for the determination of a universal calibration law [9] in size-exclusion chromatography (SEC).

2. Experimental. - 2.1 POLYMERS AND SOLVENTS. - Seven different linear polystyrene samples, with molecular weights ranging from $8 \times 10^{3}$ to $2.7 \times 10^{6}$, and two polystyrene combs (PSC1 and PSC2) were used. All samples had a narrow molecular weight distribution. All experiments were carried out with freshly distilled tetrahydrofuran (THF).

2.2 TECHNIQUES. - Ultracentrifugation experiments were performed at four or five different concentrations, using a Spinco-Beckman model E apparatus, and extrapolated to zero concentration. The SEC experiments were made with a classical Waters Associates model 200 apparatus and a six column set (Styragel) with exclusion limits of $10^{7}, 10^{6}, 10^{5}, 10^{4}$, $3 \times 10^{3}$ and $500 \AA$. The flow rate of elution solvent (THF) was $1 \mathrm{~cm}^{3} \mathrm{~min}^{-1}$.

3. Results and discussion. - Numerical values of the different transport parameters, intrinsic viscosity $[\eta]$, sedimentation coefficient $S$ and elution volume $V_{\mathrm{e}}$ (in SEC) are listed in table I. In figure 1 a log-log plot of $[\eta]$ and $S$ against molecular weight shows the expected slope in the range of low molecular weight. For $M<4 \times 10^{4}$ the results agree with those for an ideal chain, namely an exponent of 0.5 in both cases. Figure 2 illustrates the variations of the product $[\eta] S M^{-1}$ which, like $[\eta] D$, should be proportional to $R_{\mathrm{G}}^{2} M^{-1}$

Table I. - Variation of the limiting sedimentation coefficient $S$, the intrinsic viscosity $[\eta]$ and the elution volume $V_{\mathrm{e}}$ for linear (PSi, $\left.i=1-7\right)$ and comb-shaped (PSC1 and PSC2) polystyrene samples dissolved in tetrahydrofuran at $20^{\circ} \mathrm{C} . M$ is the peak molecular weight, defined as $M=\left(M_{\mathrm{w}} M_{\mathrm{n}}\right)^{1 / 2}, M_{\mathrm{n}}$ and $M_{\mathrm{w}}$ being the average number and weight molecular weights.

\begin{tabular}{|r|r|c|c|l|}
\hline Sample & \multicolumn{1}{|c|}{$\begin{array}{c}M \\
\text { g.mole }\end{array}$} & $\begin{array}{c}\left.\text { [ }{ }^{-1}\right] \\
\left(\mathrm{cm}^{3} \cdot \mathrm{g}^{-1}\right)\end{array}$ & $\begin{array}{c}S \\
(\text { Svedberg })\end{array}$ & $\begin{array}{c}V_{\mathrm{e}} \\
\left(\mathrm{cm}^{3}\right)\end{array}$ \\
\hline PS1 & 8000 & 11.4 & 1.33 & 227.25 \\
PS2 & 19750 & 15.3 & 2.19 & 220.5 \\
PS3 & 40000 & 23.3 & 2.93 & 212.5 \\
PS4 & 120200 & 60.5 & 4.20 & 200.5 \\
PS5 & 313000 & 113.2 & 6.90 & 191.25 \\
PS6 & 655000 & 183.4 & 10.13 & 182.5 \\
PS7 & 2700000 & 585.0 & 17.7 & 171.0 \\
PSC1 & 147000 & 19.0 & 6.87 & 205.6 \\
PSC2 & 294000 & 28.2 & 9.14 & 201.15 \\
\hline
\end{tabular}

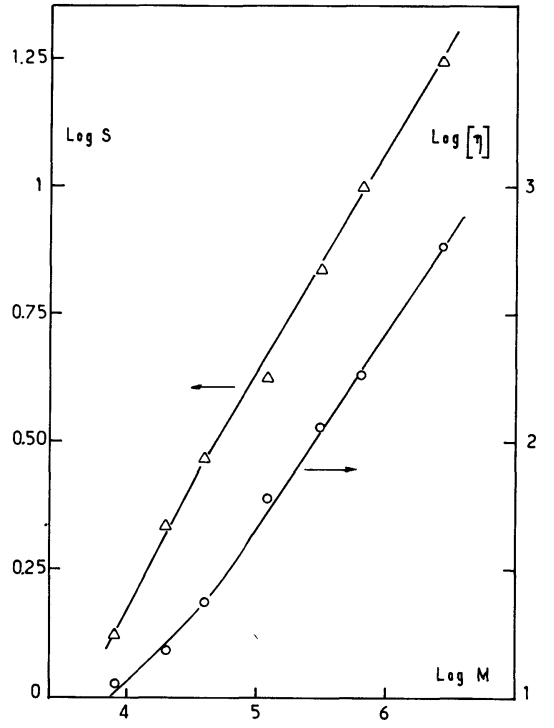

Fig. 1. - Variations of the limiting sedimentation coefficient $S$ and the intrinsic viscosity [ $\eta$ ] with molecular weight (logarithmic scales) for linear polystyrene samples dissolved in tetrahydrofuran at $20^{\circ} \mathrm{C}$.

(see eq. (2)). The results observed previously with a different solvent [7] are confirmed, that is :

(i) The chain apparently has an ideal chain behaviour for $M<4 \times 10^{4}$, as already noticed in figure 1 . This result seems to be quite general and we tested it with the data published by Rossi et al. [10], who performed diffusion and viscosity experiments with 12 different low molecular weight polystyrene samples. As seen in table II, despite some scattering in the data, the product $[\eta] D$ is constant for $M<6 \times 10^{3}$, corroborating our results. It might be objected that equations (1) assume impermeability, which is probably not true for low polymerization degrees $[6,11,12]$. However, static experiments, using X-ray [13] or smallangle neutron scattering [14], confirm the dynamic data. In addition, let us observe that, to define the degree of swelling $\alpha$ of a chain, the constancy of the ratio $R_{\mathrm{G}}^{2} / M$ for short chains provides a reference state probably better suited than the $\theta$-solvent conditions.

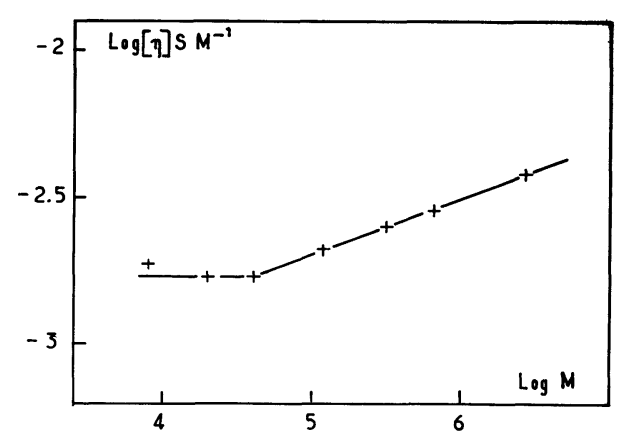

Fig. 2. - Variations of the products $[\eta] S M^{-1}$ with molecular weight (logarithmic scales) for linear polystyrene samples dissolved in tetrahydrofuran at $20^{\circ} \mathrm{C}$. 
Table II. - Variation of the product [ $\eta] D$ with molecular weight, for polystyrene samples dissolved in benzene at $20^{\circ} \mathrm{C}$, according to data published by Rossi et al. [10].

\begin{tabular}{|c|c|c|c|c|c|c|}
\hline $\begin{array}{c}M \times 10^{-3} \\
\mathrm{~g} \cdot \mathrm{mole}^{-1}\end{array}$ & 0.660 & 1.450 & 1.690 & 1.880 & 2.320 & 2.620 \\
\hline $\begin{array}{c}{[\eta] D \times 10^{7}} \\
\mathrm{~cm}^{5} \cdot \mathrm{g}^{-1} \cdot \mathrm{s}^{-1}\end{array}$ & 1.18 & 1.16 & 1.15 & 1.17 & 1.18 & 1.19 \\
\hline $\begin{array}{c}M \times 10^{-3} \\
\mathrm{~g} \cdot \mathrm{mole}\end{array}$ & 3.936 & 4.475 & 5.300 & 8.320 & 17.300 & 34.500 \\
\hline $\begin{array}{c}{[\eta] D \times 10^{-1}} \\
\mathrm{~cm}^{5} \cdot \mathrm{g}^{-1} \cdot \mathrm{s}^{-1}\end{array}$ & 1.17 & 1.16 & 1.15 & 1.22 & 1.29 & 1.33 \\
\hline
\end{tabular}

Thus, figure 2 can also be viewed as a translated representation of $\log \alpha$ against $\log M$.

(ii) The rather abrupt change in the slope around a critical molecular weight (which depends on the solvent power) is a priori in favour of the simplified blob model originally proposed $[1,2]$. However, it must be recognized that static [13] and dynamic [7] results performed on the same system (polystyrene/ toluene) do not show the same spatial cross-over, as seen in figure 3. Nevertheless, such a comparison has its own limits, because of varying poly-dispersity, experimental precision and solvent quality. (Small amounts of water can affect significantly the exclusionvolume parameter, because of preferential adsorption.)

(iii) The slope of $R_{\mathrm{G}}^{2} / M$ against $M$ (logarithmic scales) provides, above the value $M_{\mathrm{c}}$, an easy way to

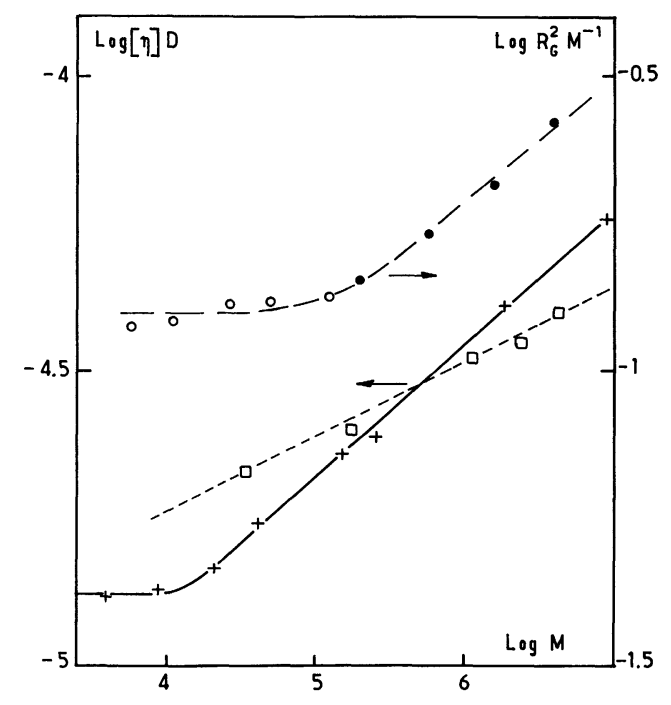

Fig. 3. - Variations of the products $[\eta] D$ and $R_{\mathrm{G}}^{2} M^{-1}$ ( $R_{\mathrm{G}}$ being the coil radius of gyration) with molecular weight (logarithmic scales) for linear polystyrene samples dissolved in toluene at $20^{\circ} \mathrm{C}$. Data taken from references [8] $(+)$; $[17-18](\square) ;[13](0) X$-ray scattering; [13](๑) light scattering. determine the critical exponent $v_{\mathrm{G}}$, as this slope is equal to $\left(2 v_{\mathrm{G}}-1\right)$. From the data presented in figure 3 and from other published power laws [7] we obtained the value $v_{\mathrm{G}} \simeq 0.59$. Our present data (see Fig. 2) lead to the same result. The excellent agreement with the values expected from renormalization theories $[15,16]$ might be coincidental, in view of the limited experimental precision, but it seems possible to suggest from dynamic measurements that $v_{\mathrm{G}}$ is definitely lower than 0.6 , which is the mean field result. Careful experiments, performed by Meyerhoff et al. [17, 18] on high molecular weight polystyrene samples dissolved in toluene $\left(20^{\circ} \mathrm{C}\right)$, lead to the following power laws :

$$
\begin{aligned}
{[\eta] } & \sim M^{0.724} \\
S & \sim M^{0.413} .
\end{aligned}
$$

This gives $v_{\mathrm{G}} \simeq 0.57$. The product of their diffusion and viscosity data is represented in figure 3 , and a slope significantly lower than the one we calculated for the same system is obtained, leading to $v_{\mathrm{G}} \simeq 0.565$.

A last comment is suggested by the foregoing results : the existence of a rather narrow cross-over domain is unexpected and unexplained. We tested our representation on a variety of polymer/solvent systems, and the result appears to have some generality. This is in contradiction with several recent theoretical developments $[3,6]$, which try to describe a smooth crossover with an « improved blob model ». The question remains open to further investigation.

In size-exclusion chromatography some authors have suggested $[19,20]$ that the "hydrodynamic volume " $[\eta] M$ is not the appropriate coil dimension to determine a universal calibration curve, as first proposed by Benoit et al. [21]. Instead, Nagasawa et al. [20] propose the use of the radius of gyration as the bestsuited size parameter. With our set of data, it is possible to check whether the different coil dimensions, i.e.

$R_{\mathrm{D}} \sim M S^{-1} ; \quad R_{\mathrm{G}}^{2} \sim[\eta] S ; \quad R_{\mathrm{D}} R_{\mathrm{G}}^{2} \sim[\eta] M$,

are appropriate for building a calibration curve. It is also a problem of practical importance, since various detection methods (elastic and inelastic light scattering, viscosity) may be coupled with an SEC apparatus. Figure 4 shows the variation against the peak elution volume $V_{\mathrm{e}}$ (see table I) of the logarithm of the different coil sizes appearing in (3). If we first disregard the experimental points corresponding to the combshaped samples, it appears that the curves are linear over a wide range of molecular weights, except for the high molecular-weight fractions. Especially, no noticeable deviation from linearity is detectable around the cross-over value $\boldsymbol{M}_{\mathrm{c}}$. In addition, the slopes of the curves, which are respectively $-0.117,-0.233$ and -0.350 , are in the expected ratio $1: 2: 3$. Therefore, if we limit the analysis to linear polymers, the three representations appear to be equivalent. However, since the different molecular dimensions follow different power laws with respect to molecular weight, the 


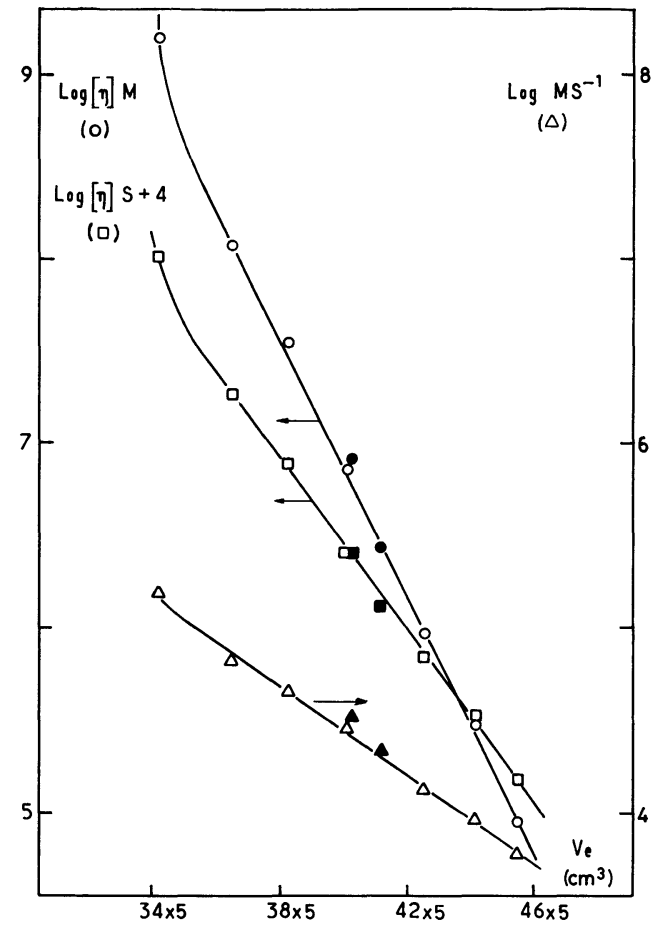

Fig. 4. - Variations of the logarithm of the products [ $\eta] M(O)$ or $(\bullet),[\eta] S(\square)$ or $(\square)$ and $M S^{-1}(\triangle)$ or $(\Delta)$ with peak elution volume in SEC, for seven linear and two comb-shaped (marked in black) polystyrene samples, in tetrahydrofuran at $20^{\circ} \mathrm{C}$.

former result implies an unexpected relation among the critical exponents $v_{\mathrm{G}}$ and $v_{\mathrm{D}}$. Nevertheless, the limited experimental accuracy prevents us from going too far in the analysis of these data.
In addition, the experimental points corresponding to the comb-shaped molecules are marked in black and, looking at their location on the different curves, we notice that no definite conclusion concerning these branched molecules can be drawn from our results.

4. Conclusion. - By combining ultracentrifugation and viscosity studies for a series of linear polystyrene samples we have shown that it is possible to study, in a wide range of degrees of polymerization, the variation with molecular weight of the radius of gyration. The existence of a spatial cross-over predicted by modern polymer theory is confirmed, and the expected power laws under and above the critical molecular weight are indeed observed. In particular, we suggest that the critical exponent $v_{\mathrm{G}}$ is definitely lower than the meanfield value 0.6 , in the asymptotic limit. In size-exclusion chromatography, our preliminary results indicate that no coil dimension is obviously the best for building a universal calibration curve.

Nevertheless, there are difficulties inherent in such a study, especially in the short-chain domain; they are related to :

(i) The problem of experimental accuracy;

(ii) The variation of the polymer specific volume with molecular weight [22], neglected in equation (1c);

(iii) The validity of equation $(1 a)$ when the polymer coil becomes permeable to the solvent [6].

Thus, to go one step further, it would probably be wise to study the chain dynamics near the $\theta$ conditions, where the cross-over domain corresponds to higher molecular weights.

\section{References}

[1] DaOud, M., Thèse, Université Paris 6 (1977).

[2] Weill, G., Des Cloizeaux, J., J. Physique 40 (1979) 99.

[3] AkcazU, A. Z., HaN, C. C., Macromolecules 12 (1979) 276.

[4] François, J., Schwartz, T. and Weill, G., Macromolecules 13 (1980) 564.

[5] Akcazu, A. Z., Benmouna, M. and Alkhafaji, S., Macromolecules 14 (1981) 147.

[6] Ullman, R., Mácromolecules 14 (1981) 746.

[7] Schmitt, A., J. Physique Lett. 40 (1979) L-317.

[8] Mukherjea, R. N., Rempp, P., J. Chim. Phys. 56 (1959) 94.

[9] Grubisic, Z., Rempr, P. and Benoit, H., Polym. Lett. 5 (1967) 753.

[10] Rossi, C., Bianchi, U. and Bianchi, E., Makromol. Chem. 41 (1960) 31.

[11] Dewan, R. K., van Holde, K. E., J. Chem. Phys. 39 (1963) 1820.

[12] Couper, A. and Stepto, F. T., Trans. Faraday Soc. 65 (1969) 2486.
[13] Kirste, R. G. and WiLD, G., Makromol. Chem. 121 (1969) 174.

[14] Duplessix, R., Duval, M., François, J. and Sarazin, D., Polymer 22 (1981) 287.

Duval, M., Thèse, Université L. Pasteur, Strasbourg (1982).

[15] Le Guillou, J. C. and Zinn-Justin, J., Phys. Rev. Lett. 39 (1977) 95.

[16] Des Cloizeaux, J., J. Physique 42 (1981) 635.

[17] Appelt, B. and Meyerhoff, G., Macromolecules 13 (1980) 657.

[18] RaCZeK, J. and Meyerhoff, G., Abstracts of Communications, 27th IUPAC Symp. on Macromol., Strasbourg, July 1981.

[19] Pannel, J., Polymer 13 (1972).

[20] Kato, T., Itsubo, A., Yamamoto, Y., Fujimoto, T. and Nagasawa, M., Polymer J. 7 (1975) 123.

[21] Benoit, H., Grubisic, Z., Rempp, P., Decker, D. and Zilliox, J. G., J. Chem. Phys. 63 (1966) 1507.

[22] Sarazin, D. and François, J., Polymer 19 (1978) 694. 